\title{
Evaporative cooling efficiency of pads consisting of vegetable loofah
}

\author{
Júlio César Ferreira de Melo Júnior*, João Victor Martins Bamberg, Neiton Silva Machado, \\ Emanuelly Nadja Gomes Caldas, Marcos Sales Rodrigues
}

Federal University of San Francisco Valley

*Corresponding author, e-mail: julio.melo@oi.com.br

\begin{abstract}
Brazilian agroindustry has presented constant innovations in the use of equipment and materials, among which are those that generate artificial thermal conditioning inside the zootechnical facilities, through a direct evaporative cooling system (DEC). In order to mitigate the effects of high temperatures associated with low air humidity in buildings in the northeastern region of Brazil, the use of DEC systems is evident. Therefore, DEC's built with evaporative pads constituted of alternative materials, prove to be an interesting and viable alternative. The aim of this work was to evaluate the cooling efficiency of the evaporative pads constituted of vegetable loofah. The experiment was performed at the Campus de Ciências Agrárias, Federal University of the São Francisco Valley (UNIVASF) in Petrolina, Pernambuco state. The experimental design was in randomized blocks, in a $4 \times 4$ factorial scheme, with 13 replicates. Air temperature and relative humidity values were collected before and after the passage through the pad for different flow velocities and pad thicknesses, in order to calculate the evaporative efficiency. The variance analysis was significant at $5 \%$ probability for the sources of variation of the pad thickness $(0.05,0.075,0.1$ and $0.125 \mathrm{~m})$ and the air flow rate $\left(0.076,0.264,0.459\right.$ and $\left.0.773 \mathrm{~m} \mathrm{~s}^{-1}\right)$, and the interactions. The highest efficiency, $57.0 \%$ was observed for the interaction between the thickness of $0.125 \mathrm{~m}$ and the speed of $0.773 \mathrm{~ms}^{-1}$ as adjusted model.
\end{abstract}

Keywords: Luffa cylindrica, evaporative cooling, wind tunnel

\section{Introduction}

In the agricultural systems, the influence of the climatic elements is decisive in meeting the productive potential of the crops; therefore, the previous knowledge of these elements will positively interfere in the yield, sustainability and economy of these systems (Jadoski et al., 2006; Maggi et al., 2008). Meteorological elements, such as humidity and air temperature, when controlled, aid to stablish the thermal comfort in zootechnical and agricultural environments; in the case of the weather or the climate, they do not provide the conditions for the expression of the highest animal and vegetal productive potential.

The agricultural industry in the country has presented constant innovations as to equipment and materials utilized in the zootechnical and agricultural facilities, among these the utilization of equipment which promote the thermal conditioning in the interior of the buildings, through a direct evaporative cooling system (DEC).

The DEC's have, as principle, the cooling of the air through the conversion of the sensible heat energy by utilizing it in water evaporation. These systems are utilized in several zootechnical installations and plant nurseries, presenting a satisfactory performance, as evidenced by Perin et al. (2016), when they evaluated primiparous 
and multiparous sows and piglets subjected to environments climatized with DEC. Cellulose pads are usually employed in these systems, but these present negative aspects, for presenting elevated cost and little durability (Vigoderis et al., 2007). In this perspective, several authors (Vigoderis et al., 2007; Riangvilaikul \& Kumar, 2010; Oliveira et al., 2012; Maurya et al., 2014) have investigated the use of alternative materials, such as expanded clay and vegetal fibers as constituent of the evaporative pads.

The loofah sponge (Luffa cylindrica) is a plant of the Cucurbitaceae family, presenting a very complex fibrous complex, composed of cellulose (60\%), hemicellulose (30\%) and lignin (10\%), with its length varying from $15 \mathrm{~cm}$ to 1,5 m (Papanicolaou et al., 2015). In Brazil, the plant is cultivated in the North and Northeast regions, beside the states of São Paulo, Minas Gerais and Mato Grosso, and is widely utilized as bath sponge. Furthermore, its fibers work as reinforcement in thermoplastics, filters for the military and in reinforced glass fibers with compound polymers, in marine industries (Seki et al., 2012; Chen et al., 2014). Among its positive factors are the low density, non-toxicity, recyclability and low production cost (Seki et al., 2012), becoming an interesting alternative as natural fiber in the usage of thermal conditioning systems. Little is known about the dimensioning, cooling efficiency and ideal air velocity in the interior of the agro-industrial facilities equipped with evaporative pads of alternative materials.

In this manner, the present work aimed to determine the best thickness for producing evaporative cooling pads constituted of vegetal loofah, and the adequate air flow velocity which passes through the panel, based on the higher process efficiency.

\section{Material and Methods}

The experimental phase of the present work was performed in the Laboratório de Construções Rurais e Ambiência, placed in the Campus de Ciências Agrárias (CCA) of the Federal University of the São Francisco Valley (UNIVASF) in the municipality of Petrolina, PE state.
According to the climatic classification of Köppen, the region presents a climate of the BSwh' type, steppe hot arid, with the occurrence of the rainy period in the summer (Melo Júnior et al., 2014).

For the evaluation of the natural vegetal fiber as a constituent material of the evaporative pad, four pads of different thicknesses were built $(0,05,0,075,0,10$ and $0,125 \mathrm{~m})$, and filled with the giant vegetal loofah. In the performing of the experimental trials, four air flow velocities were utilized through the evaporative pad, obtained through the control of the opening of the wind tunnel conic bulkhead, which were: 0,076 $\pm 0,001$; $0,264 \pm 0,005 ; 0,459 \pm 0,006 ; 0,773 \pm 0,007 \mathrm{~m} \mathrm{~s}^{-1}$. Therefore, the utilized experimental design was in randomized blocks, in a $4 \times 4$ factorial scheme, with 13 replications.

The evaporative pads possessed a transversal flow area of $0,9312 \mathrm{~m}^{2}$ and correspondent volumes to the thicknesses of $0,05,0,075,0,1$ and $0,125 \mathrm{~m}$, of 0,0466, 0,0698, 0,0931 and $0,1164 \mathrm{~m}^{3}$. Furthermore, for the referred thicknesses of the evaporative pads, an average density equal to $19,12 \pm 0,89 \mathrm{~kg} \mathrm{~m}^{-3}$ was obtained. This value was obtained by weighing the pads after the laying of the vegetal material due to the gravitational force after three cycles of wetting and drying.

The evaluation phases were performed in a reduced wind tunnel prototype, built by TNC Climatizadores company in Petrolina - PE (Figure 1). The prototype was based in the methodology of Liao \& Chiu (2002), who developed a reduced wind tunnel for the study of materials for evaporative cooling systems, and concluded that the prototype could be fit for the experiments concerning the study of alternative materials. The working of the process occurs through the creation of a negative pressure inside the duct by the activation of the exhauster, which forces the air passage through the previously moistened plate of the wetting system, cooling it, being the orientation of the air flow presented in Figure 1, from "a" to "g".

Presented in Figure 1, specifically the letter "h" represents the sprinkler bar over the evaporative pad. This bar was connected through a PVC pipe to a hydraulic pump of $184 \mathrm{~W}$ 
of power, constituting the wetting system of the evaporative pad. In the experiment, a constant water mass flow was adopted for the treatments, equivalent to $92,2 \pm 1,3 \mathrm{~g} \mathrm{~s}^{-1}$, determined through the gravimetric method according to Oliveira et al. (2012).

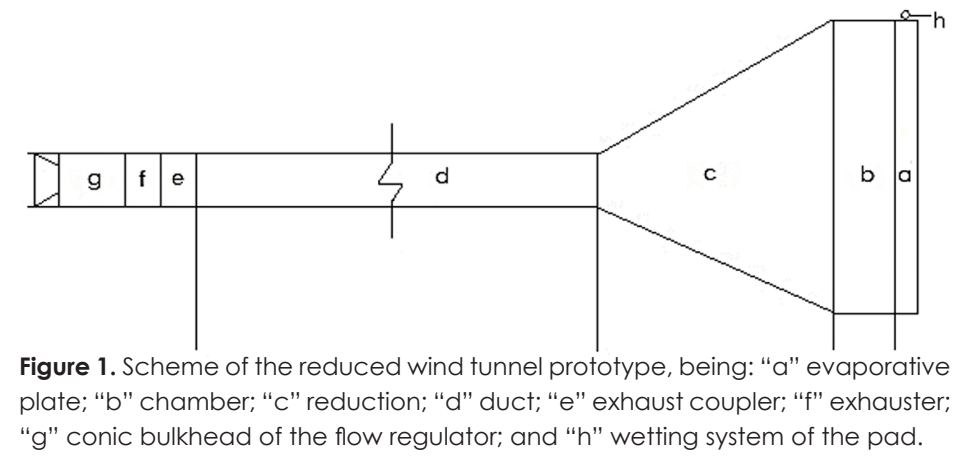

The values of the dry and wet bulb temperatures of the external air, and the dry bulb temperatures of the internal air, for the evaluation of the thicknesses of the pads front four different air flow velocities, were obtained through a digital psychrometer (model PY5080; Icel brand; precision for air temperature of $\pm 0,5^{\circ} \mathrm{C}$ and humidity of $\pm 3 \%$ ) and a data logger of temperature and air relative humidity of the Onset brand (model Hobo U12-013; with temperature precision of $\pm 0,35^{\circ} \mathrm{C}$ and humidity of $\pm 2,5 \%$ ), being this equipment responsible for the monitoring of the variables inside the wind tunnel. The data logger was positioned at a distance of two meters from the internal face of the evaporative pad.

The efficiency of the pad evaporative cooling ( $\eta$ ) was calculated through the equation 1 proposed by Ashrae (1983).

$$
\eta=\frac{\mathrm{T}_{\mathrm{s} 1}-\mathrm{T}_{\mathrm{s} 2}}{\mathrm{~T}_{\mathrm{s} 1}-\mathrm{T}_{\mathrm{U} 1}}
$$

in which:

$\mathrm{T}_{\mathrm{s} 1}=$ air temperature, measured in the dry bulb of the psychrometer, before passing through the evaporative pad $\left({ }^{\circ} \mathrm{C}\right)$;

$\mathrm{T}_{\mathrm{s} 2}=$ air temperature, measured in the dry bulb of the psychrometer, after passing through the evaporative pad $\left({ }^{\circ} \mathrm{C}\right)$;

$\mathrm{T}_{\mathrm{ul}}=$ air temperature, measured in the wet bulb, before passing through the evaporative $\operatorname{pad}\left({ }^{\circ} \mathrm{C}\right)$.

The efficiency values of the evaporative cooling were subjected to variance analysis by applying the F test at the level of $5 \%$ probability. The means concerning the factors: pad thickness and flow velocity through the evaporative pad for air cooling were subjected to the ScottKnott test and regression analysis, respectively. Furthermore, the interactions within the factors were significant, and these were subjected to regression analysis, evaluating the coefficients through the t test at $5 \%$ significance. The statistical analyses were performed by utilizing the SISVAR v.5.3 computational software (Ferreira, 2014).

\section{Results and Discussion}

The result of the analysis of variance for the evaporative efficiency in function of the factors: thickness and air flow velocity through the evaporative pad is represented in Table 1. It is observed that both factors and the interaction presented significant differences, at the level of $1 \%$ probability, though the $\mathrm{F}$ test.

Table 2 represents the performed statistical analysis by utilizing the Scott-Knott test for the source of variation of the evaporative pad thickness. It might be observed that significant differences occurred at the level of $5 \%$ probability within all treatments, being the highest efficiency of the evaporative pad verified for the thickness of $0,10 \mathrm{~m}$.

Vigoderis et al. (2007), when evaluating the evaporative efficiency of pads constituted by expanded clay, observed that the thickness of $0,075 \mathrm{~m}$ presented the highest efficiencies, with the values varying from 62,6 to $79,7 \%$ according to the average air velocities close to the pad. Oliveira et al. (2012), studying alternative options for evaporative pads constituted of vegetal sponge, coconut fiber and rigid cellulose, observed the highest thickness efficiencies of 
Table 1. Analysis of variance for the efficiency of the evaporative pad in function of the factors: pad thickness (E) and air flow velocity through the evaporative pad (U).

\begin{tabular}{ccccc}
\hline FV & GL & SQ & QM & FC \\
\hline Block & 12 & 456,25 & 38,02 & 7,71 \\
E & 3 & $9.336,92$ & $3.112,31$ & 630,89 \\
$U$ & 3 & $2.566,55$ & 855,52 & 173,42 \\
E*U & 9 & $5.035,28$ & 559,48 & 113,41 \\
Error & 180 & 887,97 & 4,93 & \\
\hline Total & 207 & $18.282,96$ & & \\
\hline CV(\%) & 5,4 & & & \\
Mean & 41,16 & & & \\
\hline
\end{tabular}

Table 2. Means of the evaporative cooling efficiencies and result of the application of the Scott-Knott test for the source of variation "pad thickness" (standard error equal to 0,308)

\begin{tabular}{cc}
\hline Treatments $(\mathrm{m})$ & Harmonic mean \\
\hline 0,10 & $50,57( \pm 0,88) \mathrm{a}$ \\
0,125 & $42,98( \pm 1,26) \mathrm{b}$ \\
0,075 & $39,08( \pm 0,45) \mathrm{c}$ \\
0,05 & $32,03( \pm 0,90) \mathrm{d}$ \\
\hline
\end{tabular}

$0,15 \mathrm{~m}, 77,2 \%, 79,5 \%$ and $84,6 \%$, respectively, for the air psychometric conditions standardized for the experiment.

In the experiment of this work a constant wetting flow of the vegetal fiber was adopted for all treatments, of 5,53 $\pm 0,08 \mathrm{~L} \mathrm{~min}^{-1}$. Oliveira et al. (2012) observed that the best cooling efficiency results of the evaporative pads were found for the flow of 5,36 L min-1. These authors also mentioned that for the evaluated flows, 5,36 to $6,76 \mathrm{~L}$ min 1 , the evaporative cooling efficiency virtually did not vary.

Figure 2 presents the collected results and the response surface adjusted for the observations of the evaporative pad efficiencies in function of the sources of variation: air flow velocity through the evaporative pad and thickness.

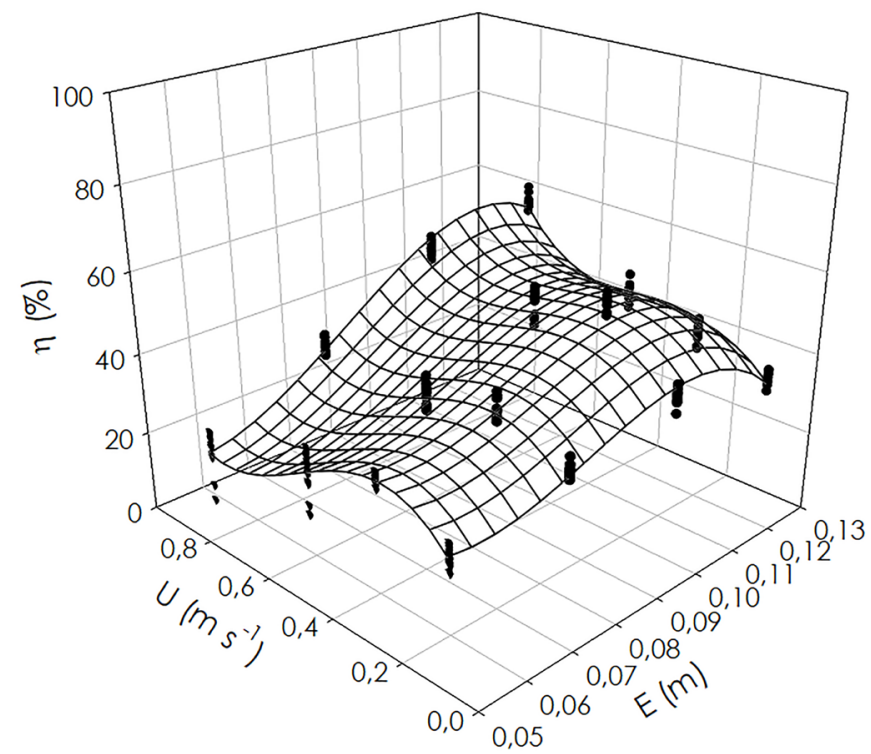

$\eta=120,5^{* *}-4.361,67^{* *} \cdot E+181,46^{* *} \cdot U+60.014,61^{* *} \cdot E^{2}-506,51^{* *} \cdot U^{2}$

$-246,9^{*} \cdot E \cdot U-250.937,14^{* *} \cdot E^{3}+314,85^{* *} \cdot U^{3}+990,46^{* *} \cdot E \cdot U^{2}$

$\mathrm{R}_{\mathrm{ajs}}^{2}=89,24 \%$

**significant parameters to $1 \%$ of probability; *significant parameter to $5 \%$ of probability.

Figure 2. Observed data and response surface adjusted for efficiency $(\eta)$ of the evaporative pad in function of the factors: air flow velocity (U) through the evaporative pad and thickness (E). 
The adjusted model presented the highest efficiency of the evaporative pad, equal to $60,2 \%$, referring to the air flor velocity through the pad of $0,773 \mathrm{~m} \cdot \mathrm{s}^{-1}$ and thickness of $0,1 \mathrm{~m}$. Efficiency values of the evaporative pad constituted of expanded clay varying from 48,08 to $79,7 \%$ were observed by Vigoderis et al. (2007) for air flow velocities close to the pad varying from 1,01 to $1,31 \mathrm{~m} . \mathrm{s}^{-1}$, respectively. Oliveira et al. (2012), investigating the efficiency of the evaporative cooling of pads with $0,15 \mathrm{~m}$ thickness constituted of vegetal fibers, sponge and coconut, observed cooling efficiencies of 77,3 and $79,9 \%$, respectively, for the air flow velocity through the evaporative pad of $0,6 \mathrm{~m} \mathrm{~s}^{-1}$. Maurya et al. (2014), evaluating the evaporative cooling efficiency for the materials: cellulosis, poplar and coconut fiber, observed maximum values of $64,55 \%, 80,99$ and $68,15 \%$, respectively, for pads with $0,1 \mathrm{~m}$ thickness and air flow velocities through the pad from 0,5 to $3,0 \mathrm{~m} \mathrm{~s}^{-1}$.
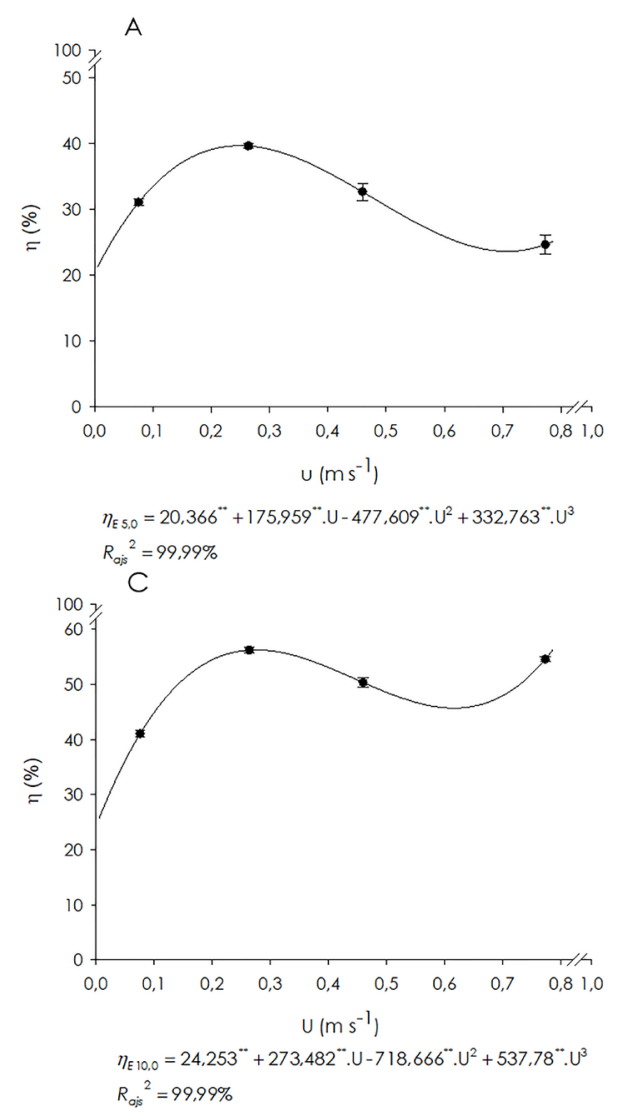

Furthermore, it is worth noting that for the highest evaporative pad thicknesses there is a growth of the efficiency tending to the infinite, what might be explained by the fact that the maximum air velocity through the plate did not reach a level which allowed the occurrence of maximum efficiency of the evaporative panel, although the excessive air velocity might reduce the cooling efficiency due to the increase of charge loss in the panel. (Liao \& Chiu, 2002). Oliveira et al. (2012), attempting to minimize the above mentioned effect, choose to perform tests with air flow velocities through the pad from 0,5 to 1,2 $\mathrm{m} \mathrm{s}^{-1}$, which they classified as low. Maurya et al. (2014) observed a reduction of the evaporative cooling efficiency with the increase in the air velocity through the pad.

The statistical analysis of the evaporative cooling, in relation to the splitting of the air flow velocities through the pad, within each thickness level, is represented in Figure 3.
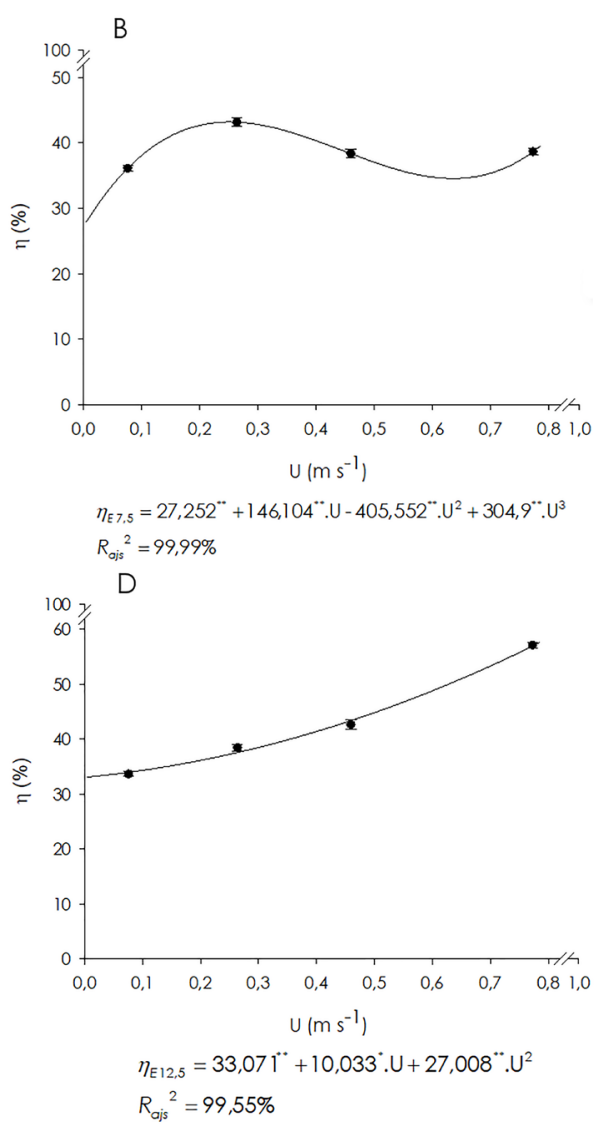

$R_{\text {ois }}{ }^{2}=99,55 \%$

**significant parameters at $1 \%$ of probability; *significant parameter at $5 \%$ of probability.

Figure 3. Regression models for the efficiency $(\eta)$ of the evaporative pad adjusted for the significant splittings which involved the thicknesses of $0,05 \mathrm{~m}(\mathrm{~A}) ; 0,075 \mathrm{~m}(\mathrm{~B}) ; 0,1 \mathrm{~m}(\mathrm{C})$ and $0,125 \mathrm{~m}$ (D) and the air velocities through the evaporative pad (U). 
Figure 3 presents the observed values for the evaporative efficiency, as well as the adjustments of the polynomial regression models. The highest evaporative efficiency of the pad constituted with the vegetal sponge, $57,0 \%$, was observed for the interaction between the thickness of $0,125 \mathrm{~m}$ and the speed of $0,773 \mathrm{~m}$ $\mathrm{s}^{-1}$, according to the adjusted regression model (Figure 3D). Furthermore, the adjusted models presented elevated coefficients of determination $\left(R^{2}\right)$, equal or superior to 0,9955 .

Most of the adjusted polynomial models possess grade three, what implied in the obtaining of the maximum efficiencies, $39,7,43,2$ and $56,3 \%$ for each pad thickness (Figures $3 A, 3 B$ and $3 C$ ), in relation to the air flow velocities through the pad of $0,249,0,251$ and $0,275 \mathrm{~m} \mathrm{~s}^{-1}$, respectively, with slight tendency to the increase of the efficiency with the increase of the velocities from $0,65 \mathrm{~m} \mathrm{~s}^{-1}$. In Figure 3D, the adjusted polynomial
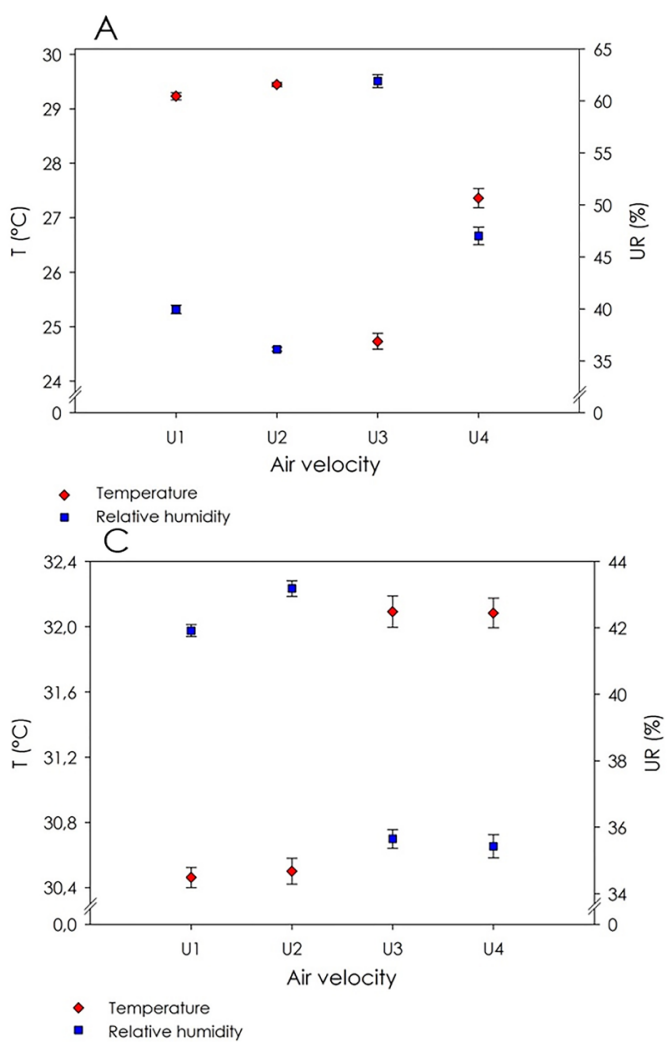

regression model was of second degree with upward concavity. This fact justifies the presented discussion when the response surface of the evaporative efficiency was considered (Figure 2), highlighting, once more, that for thicker pads the maximum air flow velocity through these was insufficient for reaching the highest evaporative efficiency of the pad with $0,125 \mathrm{~m}$ thickness.

The evaporative pads were moistened with a constant average flow of $92,2 \pm 1,3 \mathrm{~g} \mathrm{~s}^{-1}$, being this value within the flow interval evaluated by Oliveira et al. (2012), where these authors did not observe a significant influence within the wetting flows of from $89,3 \pm 0,73$ to $112,4 \pm 0,78$ $\mathrm{g} \mathrm{s}^{-1}$.

The values of the temperature and air relative humidity means, which represented the air psychometric conditions, in which the pads evaluations were performed, are presented in Figure 4.
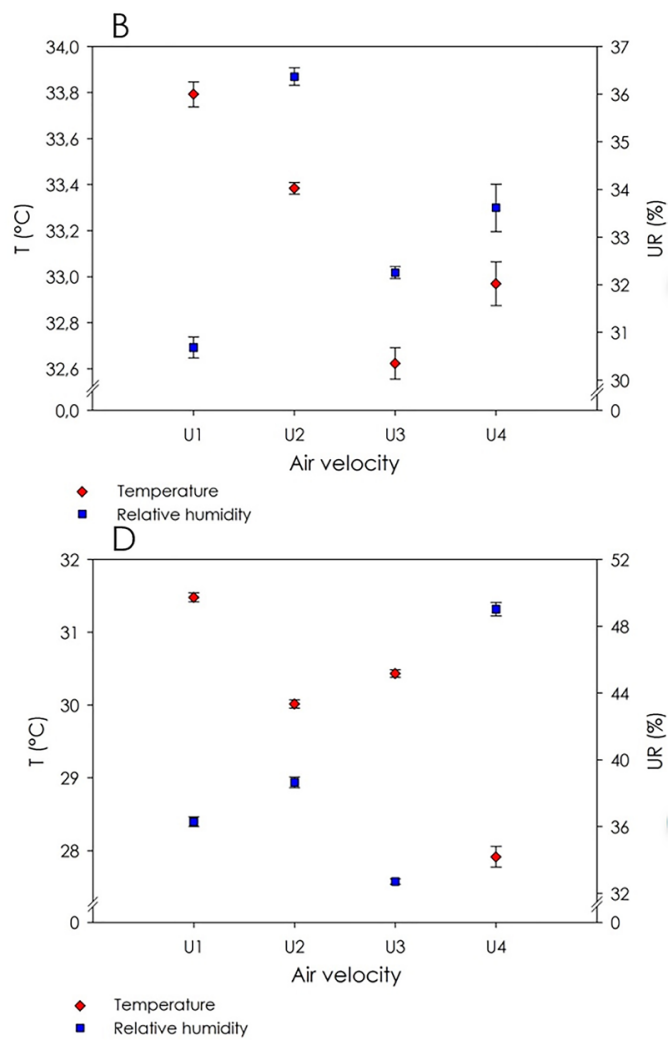

Figure 4. Temperature (T) and relative humidity (UR) means representative of the psychometric conditions of the air in which the treatments which involved the spacings $0,05 \mathrm{~m}(\mathrm{~A}) ; 0,075 \mathrm{~m}(\mathrm{~B}) ; 0,1 \mathrm{~m}(\mathrm{C})$ and $0,125 \mathrm{~m}(\mathrm{D})$ and the air velocities through the evaporative pad (U1 = 0,076 $\mathrm{m} \mathrm{s}^{-1} ; \mathrm{U} 2=0,264 \mathrm{~m} \mathrm{~s}^{-1} ; \mathrm{U} 3=0,459 \mathrm{~m} \mathrm{~s}^{-1}$; and U4 =0,773 $\mathrm{m} \mathrm{s}^{-1}$ ) were performed.

The pad evaluations were performed in psychometric conditions of temperature and air relative humidity, respectively, equal to $30,53 \pm$ $0,61^{\circ} \mathrm{C}$ and $39,42 \pm 1,98 \%$. The maximum means were $33,79{ }^{\circ} \mathrm{C}$ and $61,91 \%$, and the minimum means of $24,73^{\circ} \mathrm{C}$ of $30,68 \%$, of temperature and air relative humidity, respectively. According to Oliveira et al. (2012), the meteorological elements 
temperature and air relative humidity affect the performance of the evaporative pads, being their efficiency improved with the increase in the dry bulb temperature and in the vapor-pressure deficit of the external ambient, in a DEC system.

\section{Conclusions}

According to the proposed objectives and the obtained results, as well as to the conditions in which the experiment was performed, it is concluded that:

The highest efficiency of the adiabatic evaporative cooling system was observed for the thickness of the pad constituted of fiber of the giant vegetal loofah, equal to $0,1 \mathrm{~m}$;

In the statistical unfolding, the pad with $0,125 \mathrm{~m}$ thickness presented the highest evaporative efficiency for the highest air flow velocity $\left(0,773 \mathrm{~m} \mathrm{~s}^{-1}\right)$.

\section{Acknowledgments}

To the CNPq for the IC scholarship to the student João Victor M. Bamberg. To the TNC Climatizadores company of Petrolina-PE for the donation of the reduced wind tunnel utilized in the performing of the research.

\section{References}

Ashrae. 1983. Part 1: Air-handling equipment. In: American Society of Heating, Refrigeration and Air conditioning Engineers, ASHRAE Equipment Handbook, Ashrae, Atlanta, EUA, p. 1-10.

Chen, Q., Shi, Q., Gorb, S.N., Li, Z. 2014. A multiscale study on the structural and mechanical properties of the luffa sponge from Luffa cylindrica plant. Journal of Biomechanics 47: 1332-1339.

Ferreira, D.F. 2014. Sisvar: a guide for its bootstrap procedures in multiple comparisons. Ciência e Agrotecnologia 38: 109-112.

Jadoski, C.J., Klar, A.E., Maggi, M.F., Ramiro, J., Santos, A.B.A., Fulan, S.R. 2006. Distribuição da evaporação no interior de um ambiente protegido. Irriga 11: 246-256.

Maggi, M.F., Jadoski, C.J., Denega, S., Brunetta, L., Scabeni, C. 2008. Evaporation distribution in greenhouse using three evaporation heights. Pesquisa Aplicada \& Agrotecnologia 1: 122-125.

Liao, C., Chiu, K. 2002. Wind tunnel modeling the system performance of alternative evaporative coolings pads in Taiwan region. Building and Environment 37: 177-187.
Maurya, R., Shrivastava, N., Shrivastava, V. 2014. Performance evaluation of alternative evaporative cooling media. International Journal of Scientific \& Engineering Research 5: 676-684.

Melo Júnior, J.C.F., Lima, A.M., Teixeira, M.V., Conceição, G.C., Santos, L.R. 2014. Depleção de água no substrato e doses de fertilizante Osmocote na formação de mudas de mamoeiro. Comunicata Scientiae 5: 499-508.

Oliveira, R.S., Henríquez, J.R., Primo, A.R.M. 2012. Eficiência de painéis de fibras vegetais utilizados para sistemas de resfriamento evaporativo direto: um estudo experimental. Revista Tecnologia 33: 32-45.

Papanicolaou, G.C., Psarra, E., Anastasiou, D. 2015. Manufacturing and mechanical response optimization of epoxy resin/Luffa Cylindrica composite. Journal of Applied Polymer Science 132: 1-12.

Perin, J., Gaggini, T.S., Manica, S., Magnabosco, D., Bernardi, M.L., Wentz, I., Bortolozzo, F.P. 2016. Evaporative snout cooling system on the performance of lactating sows and their litters in a subtropical region. Ciência Rural 46: 342-347.

Riangvilaikul, B., Kumar, S. 2010. An experimental study of a novel dew point evaporative cooling system. Energy and Buildings 42: 637-644.

Seki, Y., Sever, K., Erden, S., Sarikanat, M., Neser, G., Ozes, C. 2012. Characterization of Luffa cylindrica fibers and the effect of water aging on the mechanical properties of its composite with polyester. Journal of Applied Polymer Science 123: 2330-2337.

Vigoderis, R. B., Tinôco, I. F. F., Lacerda filho, A. F., Silva, J. N., Gates, R. S., Pauli, D. G., Silva, C. E., Guimarães, M. C. C. 2007. Construção de túnel de vento reduzido, visando à avaliação de argila expandida em sistemas de resfriamento adiabático evaporativo para arrefecimento térmico em galpões de produção animal. Engenharia na Agricultura 15: 191-199. 